\title{
It is Disturbing, in Spite of the Existence of Appropriate Legislation, Illegal Distribution of Medicines
}

\section{Omer AM*}

Occupational Health Administration, Ministry of Health, Khartoum, Sudan

*Corresponding author: Abdeen Mustafa Omer, Occupational Health Administration, Ministry of Health, Energy Research Institute (ERI), Forest Road West, Nottingham NG7 4EU, UK, Fax: +44 1159513159; Tel: +44 115 9513163; Email: abdeenomer2@yahoo.co.uk

\section{Research Article}

Volume 1 Issue 1

Received Date: October 07, 2018

Published Date: November 08, 2018

DOI: $10.23880 /$ aabsc-16000108

\section{Abstract}

The strategy of price liberalisation and privatisation had been implemented in Sudan over the last decade, and has had a positive result on government deficit. The investment law approved recently has good statements and rules on the above strategy in particular to pharmacy regulations. Under the pressure of the new privatisation policy, the government introduced radical changes in the pharmacy regulations. To improve the effectiveness of the public pharmacy, resources should be switched towards areas of need, reducing inequalities and promoting better health conditions. Medicines are financed either through cost sharing or full private. The role of the private services is significant. A review of reform of financing medicines in Sudan is given in this study. Also, it highlights the current drug supply system in the public sector, which is currently responsibility of the Central Medical Supplies Public Corporation (CMS). In Sudan, the researchers did not identify any rigorous evaluations or quantitative studies about the impact of drug regulations on the quality of medicines and how to protect public health against counterfeit or low quality medicines, although it is practically possible. However, the regulations must be continually evaluated to ensure the public health is protected against by marketing high quality medicines rather than commercial interests, and the drug companies are held accountable for their conduct.

Keywords: Counterfeits Medicines; Drug Importers; Quality of Medicines; Regulatory Authorities

Abbreviations: CMSPO: Central Medical Supplies Public Organisation; CRC: Centre of Regulation and Competition; DAP: Drug Action Programme; DOP: Department of Pharmacy; FGDOP: Federal General Directorate of Pharmacy; FMOH: Federal Ministry of Health; FPPB: Federal Pharmacy and Poison Board; GMP: Good Manufacturing Practice; KS: Khartoum State; MOAR: Ministry of Animal Resources; MOH: Ministry of Health; NGOs: Non Governmental Organisations; NDP: National
Drug Policy; RDFs: Revolving Drug Funds; SPSS: Statistical Package for Social Sciences; UK: United Kingdom; USA: United States of America; WHO: World Health Organisation

\section{Introduction}

The World Health Organisation [1] has defined drug regulation as a process, which encompasses various 
activities, aimed at promoting and protecting public health by ensuring the safety, efficiency and quality of drugs, and appropriateness accuracy of information [1]. Medicines regulation is a key instrument employed by many governments to modify the behaviour of drug systems. The regulation of pharmaceuticals relates to control of manufacturing standards, the quality, the efficacy and safety of drugs, labelling and information requirements, distribution procedures and consumer prices [2]. To assure quality of medicines, in most countries registration is required prior to the introduction of a drug preparation into the market. The manufacturing, registration and sale of drugs have been the subject of restricts regulations and administrative procedures worldwide for decades [3]. Nobody would seriously argue drugs should be proven to be $100 \%$ safe. No set of regulations could achieve that goal argue, because it is impossible and all drugs carry some risk [4].

Stringent drug regulation was introduced across many countries in the 1960s following the thalidomide disaster, and had since been embraced by the industry as a commercial essential seal of safety and quality [5]. In spite of the measures, many countries, especially developing one face a broader range of problems. In several developing countries drug quality is a source of concern. There is a general feeling of high incidence of drug preparations that are not of acceptable quality [6]. For example, about $70 \%$ of counterfeit medicines were reported by developing countries [7]. Reports from Asia, Africa, and South America indicate $10 \%$ to $50 \%$ of consider using prescribed drugs in certain countries may be counterfeit [8]. For instance, in Nigeria fake medicines may be more than $60-70 \%$ of the drugs in circulation [9], and 109 children died in 1990 after being administered fake Paracetamol [10]. In Gambia the drug registration and control system resulted in the elimination of 'drug peddlers' and certain 'obsolete and harmful' drugs, as well as a large decrease in the percentage of brand and combination drugs [11]. The percentage of drugs failing quality control testing was found to be zero in Colombia, but $92 \%$ in the private sector of Chad [12]. Hence, it is very difficulty to obtain accurate data. The proportion of counterfeit drugs in the USA marketplace is believed to be small - less than 1 percent [12]. In National Drug Policy [13] reported two cases of counterfeit medicines that found their way into legitimate medicine supply chain in the UK in 2004.

Poor quality drug preparations may lead to adverse clinical results both in terms of low efficacy and in the development of drug resistance [14]. Regulations are the basic devices employed by most governments to protect the public health against substandard, counterfeit, low quality medicines, and to control prices. Thorough knowledge of whether these regulations produce the intended effects or generate unexpected adverse consequences is critical. The World Health Organisation (WHO) undertook a number of initiatives to improve medicines quality in its member states and promote global mechanisms for regulating the quality of pharmaceutical products in the international markets. Yet, there are not any WHO guidelines on how to evaluate the impact of these regulations. There are numerous reports concerning drug regulations [15], but the published work on the impact of these regulations on the quality of medicines moving in the international commerce has been scarce. Findings from most published studies lack comparable quantitative information that would allow for objective judging whether and by how much progress on the various outcomes have been made by the implementation of the pharmaceutical regulations. To ignore evaluations and to implement drug regulation based on logic and theory is to expose society to untried measures in the same way patients were exposed to untested medicines [15].

The present policy of the national health-care system in Sudan is based on ensuring the welfare of the Sudanese inhabitants through increasing national production and upgrading the productivity of individuals. A health development strategy has been formulated in a way that realises the relevancy of health objectives to the main goals of the national development plans. The strategy of Sudan at the national level aims at developing the Primary Health Care (PHC) services in the rural areas as well as urban areas. In Sudan 2567 physicians provide the public health services (554 specialists, 107 medical registrars, 1544 medical officers, 156 dentists, and 206 pharmacists). Methods of preventing and controlling health problems are the following:

Promotion of food supply and proper nutrition; An adequate supply of safe water and basic sanitation; Maternal and child health-care;

Immunisation against major infectious diseases; Preventing and control of locally endemic diseases; and Provision of essential drugs.

This will be achieved through a health system consisting of three levels (state, provincial and localities), including the referral system, secondary and tertiary levels. Pharmacy management should be coordinated and 
integrated with other various aspects of health. The following are recommended:

- The community must be the focus of benefits accruing from restructures, the legislature should protect community interest on the basis of equity and distribution, handover the assets to the community should be examined; and communities shall encourage the transfer the management of health schemes to a professional entity.

- The private sector should be used to mobilise and strengthen the technical and financial resources from within and outside the country to implement the services, with particular emphasis on utilisation of local resources.

- The government should provide the necessary financial resources to guide the process of community management of pharmacy supplies. The government should be a facilitator through setting up standards, specifications and rules to help harmonise the private sector and establish a legal independent body by an act of parliament to monitor and control the providers. Government should assist the poor communities who cannot afford service cost, and alleviate socialeconomic negative aspects of privatisation.

- The sector actors should create awareness to the community of the roles of the private sector and government in the provision of health and pharmacy services.

- Support agencies should assist with financial and technical support, training facilities, coordination, development and dissemination of health projects, as well as evaluation of projects.

\section{Aims and Objectives}

The main purpose of this study is to analyse and determine the opinion of a group of pharmacists who are the owners or shareholders in the Sudanese medicine importing companies and their perception concerning the effects of the government's new Pharmacy, Poisons, Cosmetics and Medical Devices Act has had on the quality of medicines in Sudan. To achieve this purpose the following questions would be answered:

Do the Sudan pharmacy legislations prohibit marketing of low quality medicines?

1) What is the impact of the transfer of veterinary medicines registration system to the Ministry of Animal Resources after the approval of the Pharmacy and Poisons Act 2001?

Omer AM. It is Disturbing, in Spite of the Existence of Appropriate Legislation, Illegal Distribution of Medicines. Ann Adv Biomed Sci 2018, 1(1): 000108.
2) Does pre-marketing analysis of medicines help to detect the counterfeit medicines?

3) Does importation of non-registered ${ }^{1}$ medicines by the government and non- governmental organisations exacerbate the problem of low quality medicine if any?

In Sudan, the researchers did not identify any rigorous evaluations or quantitative studies about the impact of drug regulations on the quality of medicines and how to protect public health against counterfeit or low quality medicines, although it is practically possible. However, the regulations must be continually evaluated to ensure the public health is protected against fake medicines by ensuring the exclusive marketing of high quality medicines rather than commercial interests, and the drug companies are held accountable for their conducts [16].

\section{Medicines Legislation Framework In Sudan}

The availability of medicines in Sudan is controlled on the basis of safety, quality and efficacy. Thus, the government effects control in accordance with the Pharmacy, Poisons, Cosmetics and Medical Devices Act 2001 and its instruments. The Federal or State Departments of Pharmacy (DOP) and directives issued orders. The primary objective of both Federal and States' Departments of Pharmacy is to safeguard public health by ensuring all medicines and pharmaceuticals on the Sudan market meet appropriate standards of safety, quality and efficacy. The safeguarding of public health is achieved largely through the system of medicines' registration and licensing of pharmacy premises.

The first Pharmacy and Poisons Act was enacted in 1939. This Act had been amended three times since then. In 2001 amendments, cosmetics and medical devices were also brought under its purview. Thus, the name was changed to Pharmacy, Poisons, Cosmetics and Medical Devices Act (hereafter the Act). The Act regulates the compounding, sale, distribution, supply, dispensing of medicines and provides different levels of control for different categories, e.g., medicines, poisons, cosmetics, chemicals for medical use and medical devices.

\footnotetext{
${ }^{1}$ All medicines should be registered by the General Directorate of Pharmacy to get marketing approval. Each manufacturer or importer must present extensive information on the product (or products) submitted to allow Technical Standing Committee for drug registration evaluates the quality, safety, efficacy and price of medicines.
} 
The Act makes provision for the publication of regulations and guidelines by the Federal Pharmacy and Poisons Board (FPPB), the pharmaceutical regulatory authority and its executive arm - the Federal General Directorate of Pharmacy (FGDOP). The FGDOP regulates mainly four aspects of medicines use: safety, quality, efficacy and price. Traditionally, governments in many countries, particularly developed nations have attempted to ensure the efficiency, safety, rational prescribing, and dispensing of drugs through pre-marketing registration, licensing and other regulatory requirements [17]. When applying to register the medicine manufacturers and importers are required to furnish the FGDOP with a dossier of information including among others, the indication of the medicine, its efficacy, side effects, contraindication, warnings on usage by high risk groups, price, storage and disposal [17].

The role of the FGDOP includes among others:

1. Regulation and control of the importation, exportation, manufacture, advertisement, distribution, sale and the use of medicines, cosmetics, medical devices and chemicals;

2. Approval and registration of new medicines - the Act requires FGDOP should register every medicine before be sold or marketed. Companies are required to submit applications for the registration of medicines for the evaluation and approval;

3. Undertake appropriate investigations into the production premises and raw materials for drugs and establish relevant quality assurance systems including certification of the production sites and regulated products;

4. Undertake inspection of drugs' whole and retail sellers owned by both public or private sectors;

5. Compile standard specifications and regulations and guidelines for the production, importation, exportation, sale and distribution of drugs, cosmetics, etc.

6. Control of quality of medicines: This will be done by regular inspection and post-marketing surveillance;

7. Licensing of pharmacy premises (i.e., pharmaceutical plants, wholesalers and retail pharmacies);

8. Maintain national drug analysis laboratories for the pre- and post- marketing analysis of medicines;

9. Coordination with states departments of pharmacy to ensure the enforcement of the Act and its rules and directives.

\section{Health and Pharmacy Systems}

The health system in Sudan is characterised by heavy reliance on charging users at the point of access (private expenditure on health is 79.1 percent), with less use of prepayment system such as health insurance. The way the health system is funded, organised, managed and regulated affects health workers' supply, retention, and the performance. Primary Health Care was adopted as a main strategy for health-care provision in Sudan and new strategies were introduced during the last decade, including:

Health area system.

Polio eradication in 1988.

Integrated management of children illness (IMCI) initiative.

Rollback malaria strategy.

Basic developmental need approach in 1997.

Safe motherhood, making pregnancy safer initiative, eradication of harmful traditional practices and emergency obstetrics' care programmes.

The strategy of price liberalisation and privatisation had been implemented in Sudan over the last decades, and has had a positive result on the government deficit. The investment law [18] approved recently has good statements and rules on the above strategy in particular to health and pharmacy areas. The privatisation and price liberalisation in healthy fields has to re-structure (but not fully). Availability and adequate pharmacy supplies to the major sectors. The result is that the present situation of pharmacy services is far better than ten years ago.

The government of Sudan has a great experience in privatisation of the public institutions, i.e., the Sudanese free zones and markets, Sudan telecommunications (Sudatel) and Sudan airlines. These experiences provide good lessons about the efficiency and effectiveness of the privatisation policy. Through privatisation, the government is not evading its responsibility of providing health-care to the inhabitants, but merely shifting its role from being a provider to a regulator and standard setter. Drug financing was privatised early in 1992. Currently, the Federal Ministry of Health (FMOH) has privatised certain non-medical services in hospitals such as catering services, security and cleanings.

The overall goal of the CMS ownership privatisation is to improve access to essential medicines and other medical supplies in order to improve health status of the inhabitants particularly in far states (e.g., Western and Southern States). 
Establishment of alternative ownership for the CMS can be achieved by selling the majority of shares to the private sector. This will achieve the following objectives:

- High access to essential medicines of good quality and affordable prices to the states' population and governments.

- Efficiency and effectiveness in drug distribution system to avoid the serious pitfalls and incidences that was reported during the last ten years in the CMS.

- Equity by reaching all remote areas currently deprived from the formal drug distribution channels.

- Improvement of the quality and quantity of delivery of medicines to the public health facilities.

- The above objectives are expected to:

- Increase geographical and economic access to essential medicines in all states (i.e., in both rural and urban areas) to reach at least $80 \%$ of the population (currently less than $50 \%$ of population have access to essential medicines).

- The tax collection from the new business becomes more efficient and will increase after privatisation. The tax revenues could be used to finance other health-care activities.

- If the government reserves some shares (not more than $50 \%$ ) in the new business, then its shares' profit could be used to finance free medicines project in hospitals outpatients' clinic, and other exempted medicines, e.g., renal dialysis and haemophilic patients' treatment.

\section{Privatisation of Public Pharmaceutical Supplies}

The term privatisation has generally been defined as any process that aims to shift functions and responsibilities (totally or partially) from the government to the private. More broadly meaning, it refers to the restriction of government's role and putting forward some methods or policies in order to strengthen the free market economy [19]. Privatisation can be an ideology (for those who oppose government and seek to reduce its size, role, and costs, or for those who wish to encourage diversity, decentralisation, and choice) or a tool of government (for those who see the private sector as more efficient, flexible, and innovative than the public sector) [19]. In WHO [19] contends that "the invisible hand of the market is more efficient and responsive to the consumer needs and the public administrative budgets consume large portion of tax monies that could otherwise be used for service delivery". The emphasis is on improving the efficiency of all public enterprises, whether retained or divested.

Privatisation may take many forms including:
- Elimination of a public function and its assignment to the private sector for financial support as well as delivery (police, and fire departments, schools, etc.). Opponents characterise this as "load-shedding".

- Deregulation: the elimination of government responsibility for setting standards and rules concerning goods or services.

- Assets sales: the selling of a public asset (city buildings, and sports stadiums) to private firms.

- Vouchers: are the government provided or financed cards or slips of paper that permit private individuals to purchase goods or services from a private provider (food stamps) or circumscribed list of providers.

- Franchising: the establishment of models by the public sector that is funded by government agencies, but implemented by approved private providers.

- Contracting: the government financing of services, choice of service provider, and specification of various aspects of the services laid out in contracts with the private-sector organisation that produces or delivers the services.

- User fees: public facilities such as hospitals that maximise their income or finance some goods from private sources, either through drug sales or other services. This kind of privatisation has been applied in Sudan since the early 1990s, as the health financing mechanism (especially for medicines).

In Sudan, the government has decided to distance itself from direct involvement in business, and thus divest most of its interests whether in loss or profit making public enterprises. The public reform programme was set firmly in the context of the broader reforms [19], which were introduced in 1992. It had become clear the previous policies had delivered led to poor results. This reform based on the transfer of activities vested with the government institutions to the private sector. It signalled the government intention to reduce its presence in the economy, to reduce the level and scope of public spending and to allow market forces to govern economic activities. Privatisation also forms part of the government strategy of strengthening the role of the private in the development to achieve the vision of the 25 years strategy in which the private sector will be the engine for economic growth. The privatisation started in 1992 by liberalisation of local currency, foreign exchange transactions, internal and external trade, prices and health services (e.g., user fee as a mechanism of drug financing and other services). This reform had led to greater reliance on individual initiative and corporate accountability rather than on government as a decisionmaker in business matters. 


\section{Annals of Advanced Biomedical Sciences}

The privatisation policy goal is to improve the performance of the public sector companies, so that they can contribute to the growth and the development of the economy by broadening ownership, participation in management, and stimulating domestic and foreign private investment.

The following are the primary objectives, which have been defined in the government's policy statement on public sector reform [19]:

- Improve the operational efficiency of enterprises that are currently in the public sector by exposing business and services to the greatest competition for the benefit of the consumer and the national economy.

- Reduce the burden of public enterprises on the government's budget by spreading the shares' ownership as widely as possible among the population.

- Expand the role of the private sector in the economy (permitting the government to concentrate on the public resources) on its role as provider of basic public services, including health, education, social infrastructure, and to compact the side effects of the privatisation.

- Encourage wider participation of the people in the ownership and management of business.

In pursuing the primary objectives the privatisation policy aims to transform the performance of most significant enterprises in the public sector and ensure liquidation of all viable and non-viable public enterprises as soon as possible through commercialisation, restructuring and divesture.

Public sector reform efforts are thus aimed at reducing government dominance and promoting a larger role for the private sector, while improving government's use of resources. Movement towards those goals in some countries is supported by components of a structural adjustment loan, which helped initiate the programme and establish the legislative and institutional base.

Opponents argue that the original objectives of state ownership were to ensure the corporate sector of the economy was in national hands rather than being controlled by either foreign investors or the minorities that enjoyed business dominance upon independence. A further objective was to use investment in state firms to accelerate development in a situation, in which private sector was reluctant to take risks.

\section{Medicines Legislation Framework in Sudan}

The availability of medicines in Sudan is controlled on the basis of safety, quality and efficacy. Thus, the government effects control in accordance with the Pharmacy, Poisons, Cosmetics and Medical Devices Act 2001 and its instruments. The Federal or State Departments of Pharmacy (DOP) and directives issue orders. The primary objective of both Federal and States' Departments of Pharmacy is to safeguard public health by ensuring all medicines and pharmaceuticals on the Sudan market meet appropriate standards of safety, quality and efficacy. The safeguarding of public health is achieved largely through the system of medicines' registration and licensing of pharmacy premises.

The first Pharmacy and Poisons Act was enacted in 1939 , and has been amended three times since. In the 2001 amendments, cosmetics and medical devices were also brought under its purview. Thus, the name was changed to Pharmacy, Poisons, Cosmetics and Medical Devices Act (hereafter the Act). The Act regulates the compounding, sale, distribution, supply, dispensing of medicines and provides different levels of control for different categories, e.g., medicines, poisons, cosmetics, chemicals for medical use and medical devices.

The Act makes provision for the publication of regulations and guidelines by the Federal Pharmacy and Poisons Board (FPPB), the pharmaceutical regulatory authority and its executive arm - the Federal General Directorate of Pharmacy (FGDOP). The FGDOP regulates mainly four aspects of medicines use: safety, quality, efficacy and price. Traditionally, governments in many countries, particularly developed nations have attempted to ensure the efficiency, safety, rational prescribing, and dispensing of drugs through pre-marketing registration, licensing and other regulatory requirements. When applying to register the medicine manufacturers and importers are required to furnish the FGDOP with a dossier of information including: the indication of the medicine, its efficacy, side effects, contraindication, warnings on usage by high risk groups, price, storage and disposal.

\section{Sudan Medicines' Quality Measures}

The following summarises the quality measures of all medicines. 


\section{Registration of Medicines}

The FGDOP is responsible for the appraisal, and registration of all medicines and other pharmaceuticals for both human and veterinary use on the Sudan market. It is also responsible for the verification of the competence of manufacturing companies, the manufacturing plants, the ability to produce substances or products of high quality before registering these companies and allowing them to apply for registration of their products in Sudan. When necessary, visits conducted to those companies and their manufacturing units, to verify their compliance with good manufacturing practice recommended by the WHO. The applicant for registration of pharmaceutical product must submit all prescribed data and the certificates required under the WHO certification scheme for a pharmaceutical product moving into international commerce, and any other information that is necessary for assuring the quality, efficiency and stability of the product through its shelf life [19].

\section{Licensing of Pharmacy Premises}

The licensing is a registration exercise to provide the DOP at state level (Federal level in case of local manufacturing plants) with the information necessary for the full implementation of the Act. Licenses are granted for a period of one year, and may be renewed at the end of December every year (applications to the relevant DOP before expiry of the current license). To improve the effectiveness of the public pharmacy, resources should be switched towards areas of need, reducing inequalities and promoting better health conditions. Medicines are financed either through cost sharing or full private. The role of the private services is significant. The present policy of the national health-care system in Sudan is based on ensuring the welfare of the Sudanese inhabitants through increasing national production and upgrading the productivity of individuals. The strategy of price liberalisation and privatisation had been implemented in Sudan over the last decade, and has had a positive result on government deficit.

There are three major licenses as follows:

\section{License A (Wholesaler License)}

The pharmaceutical importing companies have subjected to two broad categories of regulation. Those are the registration and administrative process, and the regulation of quality manufacturing standards, efficacy and information disclosure.
License A authorises the holder to sell a registered medicine to a person who buys the medicine for the purpose of sale or supply to someone else under the direct supervision of a registered pharmacist or licensed medical doctor. Licensing of the wholesalers involves identification of the wholesaler and suitability of the premise. There are 175 wholesalers in Sudan. The majority (162 wholesalers) are local agents for the goods manufactured from abroad. The rest are 13 "local manufacturer" wholesalers at Khartoum State (KS) and distribute the medicines to the whole country. Wholesalers are inspected by the state DOP before license is granted and thereafter at least once per year.

\section{License B (Retail Pharmacy License)}

Authorises the holder to sell a registered medicine to a patient on prescription or over-the counter basis under direct supervision of the registered pharmacist. The pharmacies are inspected before a license is issued and thereafter at least twice per year.

\section{License D (Manufacturer's License)}

Manufacturing includes many processes carried out in the course of making a medicinal product. A manufacturer's license covers all aspects- bulk drug, product manufacture, filling, labelling and packagingunder supervision of a registered pharmacist. There are 13 generic manufacturing sites at Khartoum State (KS). The Federal DOP inspects each one. Good manufacturing practice (GMP) is the basis of the inspection. Effective control of quality requires a manufacturer possess, and the appropriate facilities with respect to premises, equipment, staff, expertise and effective well-equipped quality control laboratory. Normally, before a license is granted, an inspection of premises is made and Federal DOP takes this into account. The local manufacturers produce 65 pharmaceutical dosage forms of essential drugs and cover $60 \%$ of the Central Medical Supplies Public Organisation (CMSPO) purchases.

In Sudan there are two types of retail pharmacy:

\section{Commercial Private Pharmacies}

These are private establishments retailing registered drugs and medical supplies at a mark-up of $18 \%$. The source of the drugs and pharmaceuticals is private wholesalers. In 2002, though unlawful, the CMSPO started to sell its non-registered medicines to the private pharmacies. By the end of 2004, there were 779 private pharmacies in Sudan. 


\section{People's Pharmacies}

These are quasi-public establishments retailing drugs and medical supplies below the market prices to improve access and availability of pharmaceuticals. They were founded in the early 1980s as a pilot study for a drug cost recovery system. Those differ from the private commercial pharmacies. Firstly, in having access to the CMSPO drugs, i.e., generic and large pack products, in addition the brand products from the private wholesalers. Secondly, the peoples' pharmacies are only owned by public organisations (e.g., hospitals, peoples' committees, trade unions and Non Governmental Organisations (NGOs)). Mark-up on cost for drugs from the CMSPO (35\%), and from private drug wholesalers (profit margin is $10 \%$ ). However, they have become commercialised now and operate in a similar way to private pharmacies. The total number of such pharmacies was approximately 200 in Sudan.

\section{Public Sector Medicines Supply System}

In Sub-Saharan Africa countries discussions about medicine distribution system reform have concentrated on ways to improve sustainability and quality of access to essential medicines. These discussions also include debate on the impact of privatisation of public drug supply organisations on effectiveness, efficiency, quality and cost of medicines in the public health facilities, as well as on the respective role of the public and private sectors.

Until the mid 1980s, some governments in Africa (i.e., Mali and Guinea) assumed responsibility for providing drugs to their citizens. The private distribution of all drugs including aspirin was illegal. In many countries, including Sudan there were two parallel government distribution systems. The public health network of hospitals and health centres gratuitously distributed drugs. In the public sector pharmacies, the drugs were sold to the public at subsidised prices.

During the 1990s, Sudan initiated a number of initiatives to establish drug-financing mechanisms as part of the health reform process and decentralised decisionmaking at a state level. In 1992 when a law was passed, medicines were no longer free of charge (i.e., privatised) in the public health system. The aim of the government is to increase equitable access to essential medicines, especially at the states' level. As a result the Central Medical Stores, which was responsible for medicines supply system of the public health facilities, became an autonomous drug supply agency, and was renamed as the
Central Medical Supplies Public Corporation (CMS) and operated on cash-and-carry basis. It was capitalised and an executive board was installed. Since states and federal hospitals have to buy their own medicines, and other medical supplies. They organised their own transport means and distribution to their primary health-care facilities and hospitals. In addition, all hospitals became financially autonomous entities and have had to organise their own medicines procurement system.

The public drug supply system has not been working well throughout Sub-Saharan Africa and this includes Sudan. There are serious shortages or no medicines at all, particularly in rural areas. A study in Cameroon found the rural health centres received only $65 \%$ of the stock designated for them, and $30 \%$ of the medicines that arrived at the centres did not reach the clients. The loss rate after arrival in hospitals was estimated at $40 \%$. In Sudan, Graff and Evarard (2003) who visited the country on a WHO mission reported, "Although the cash-and-carry system took off well, but lack of sufficient foreign exchange hampered the CMS procurement activities and resulted in low stock levels of all medicines and even stock out of life-saving products. Hospitals had to purchase the medicines from elsewhere and often had to buy from private sector. Overall hospitals' budgets were tied to allocate drug budget and sales income was not sufficient to cover the purchase of needed medicines supplies. This resulted the medicines were not available most of the times. The in- or outpatients with their prescriptions were directed to the private pharmacies. In 2003, Khartoum Teaching Hospital-the biggest hospital in Sudan (not further than $5 \mathrm{~km}$ away from the CMS) had a medicine stock of only LS 83,000 (US\$ 31). This would not fill one prescription for an anaemic patient as a result of renal failure. This is a common practice that patients or their relatives are given prescriptions to buy any pharmaceutical supplies that are needed including drugs and other disposables from private sector pharmacies.

Many ministries of health, services' providers and researchers have identified many characteristics that lead to poor performance in Africa public drug supply systems. These characteristics include:

\section{Absence of competition}

Competition is the best way to ensure the goods and services desired by the consumer are provided at the lowest economic cost. Given the customers (i.e., public health facilities) freedom of choice enables market forces to provide sustained pressures on companies to increase 
efficiency. Privatised companies generally operate in a competitive market environment.

\section{Insufficient funding}

For example in Sudan with exception of Khartoum, Gezira and Gedaref states, all other states do not have enough funds to establish an efficient drug supply system. In spite of being profit-making organisation, the CMS failed to avail such funds during the past 14 years.

\section{Inefficient use of available resources}

Since CMS was established in early 1990s working as a profit-making organisation. Due to the absence of privatisation the CMS engaged in an instalment of repackaging joint venture pharmaceutical factory in 1999 and recently announced its commitment to build a pharmaceutical city with not less than US\$ 20 million, despite the lack of life-saving medicines in the public health facilities. Such amount could be sufficient to establish a reliable supply system for all states of Sudan. The lack of prioritisation is a typical symptom and sign of most public organisations.

\section{Poor management}

There are a number of constraints inherent in operating government drug supply service.

These constraints comprise:

- Civil servants are hired, rather than persons with business experience and skills. Managers confront different challenges in public setting. They are not easily hired or fired. The lack of accountability results from the lack of shareholders, who would be free to remove incompetent administrators.

- Even if the services can recruit outside of civil service, the wages are often too low to attract experienced managers. In addition, the managers do not share in dividends or other monetary activities as do private managers and incentives for doing well are often attenuated in a bureaucracy.

- There are cultural and structural conditions that promote corruptions including enormous pressure of wages earners to support an extended family and a strong incentive to more than their fixed government wage, traditional gift giving practice and a proprietary view of public offices.

\section{Privatisation of the CMS's Ownership}

The public sector drug supply institutions have not succeeded (CMS is not exceptional) so far in organising a reliable and regular essential drug supply for the public health facilities (Huss, 1996). One of the most criticisms of the public drug supply system generally in Africa and particularly in Sudan is how badly they are internally managed. There are those who agree the greater amount of real pharmaceutical resources could be made available to the public health- care system and the access to essential medicines could be significantly increased, if managerial efficiency of the system improved (Akin, 1987). Given the limitation of the public sector - due to constraints inherent in operating a government drug supply organisation even after autonomous experience and the stabilised role of the private sector organisations such as private pharmaceutical sectors organisations (rapid increase in importing companies, manufacturers and pharmacies). Telecommunications, e.g., Sudatel is one of the obvious solutions of choice for the government pharmaceutical policy would be to privatise the ownership of the CMS to the extent possible.

\section{Advantages of Private Agencies}

There are many arguments in favour of privatisation of public institutions. Advocates of this method claim privatisation have the following advantages:

Privatisation is efficient and effective because it fosters and initiates competition. The competition among firms drives the cost down. Empirical studies clearly prove the cost of the services provided by the government is much higher than when the services are provided by private contractors. For example CMS's declared mark-up on cost (35\%) amounted to 2.3 times the private mark-up $(15 \%)$. In addition, private sector pays taxes, customs and other governmental fees (CMS exempted).

Privatisation also provides better management than the public management. Because decision making under privatisation is directly related to the costs and benefits. In other words, the privatisation fosters good management because the cost of the service is usually obscured.

Privatisation would help to limit the size of government at least in terms of the number of employees. On the other hand, it is a fact that overstaffing is common in publicly owned enterprises.

Privatisation can help to reduce dependence on a government monopoly, which causes inefficiencies and ineffectiveness in services. 
Private sector is more flexible in terms of responding to the needs of citizens. Greater flexibility in the use of personnel and equipment would be achieved for shortterm projects, part-time work, etc. Bureaucratic formalities are very common when government delivers the service. Less tolerance and strict hierarchy in bureaucracy are the reasons of the inflexibility in publicly provided services.

\section{Medicines Supply System}

The Act, for the first time in Sudan has given the responsibility of veterinary medicines to separate committees. The Ministry of Animal Resources took the law "in hand", and started the registration of veterinary medicines and the licensing of the veterinary medicines premises. The conflict in the shared authorities between the Ministry of Health and the chairman of the FPPB lead to the freezing of the Board since October 2002. The FGDOP continues in the process of medicines registration, inspection of the pharmaceutical premises and the licensing as before establishment of the FPPB.

The Act also obliges the states' governments to take all steps necessary to ensure compliance with marketing of registered medicines in licensed premises. But, the weaknesses of the regulatory infrastructure and lack of political commitment at state levels, the leakage of low quality, unregistered medicines to those states are highly suspected. This left the door widely opened for informal marketing of medicines particularly in far states. The states regulatory authorities should take the advantage of the legal authority granted by the Sudan constitution and the Pharmacy, Poisons, Cosmetics and the Medical Devices Act 2001 to enforce the regulations and increase the frequency of the inspection visits to drug companies and retail pharmacies.

Experience has shown the poor regulation of medicines can lead to the prevalence of substandard, counterfeit, harmful and ineffective medicines on the national markets and the international commerce. The Sudanese pharmaceutical legal framework was described as one of the strictest pharmaceutical system in the region. One of the great loopholes in this system was found to be the increased number of non-registered medicines-governmental sources such as the Central Medical Supplies Public Organisation (CMSPO) and notfor-profit non-governmental Organisations (NGOs). Respondents were hopeful the double standard of rules enforcement would be lifted after the new national unity government take over, arguing the current situation in which public organisations (such as the CMSPO) sell nonregistered medicines to the private pharmacies could enhance trading of counterfeit medicines and create unfair competition environment.

One of the respondent reported, "It is disturbing, in spite of the existence of appropriate legislation, illegal distribution of medicines by the CMSPO. The CMSPO continues to flourish, giving the impression the government is insensitive to harmful effect on the people of medicines distribution unlawfully, and some are of doubtful quality". During the past three years the CMSPO started to sell unregistered medicines to the private pharmacies. The CMSPO practice (he added) will undermine the inspection and medicines control activities and ultimately jeopardise the health of the people taking medication.

Not surprisingly all respondents strongly agreed the increased number of sources of non-registered medicines will lead to entrance of low quality medicines. This result is inline with the WHO recommendation, which encourages the regulatory authorities and state members ' government to register all medicines before the marketing. The medicines imported by public sector organisations are not excluded.

The FGDOP should define the norms, standards and specifications necessary for ensuring the safety, efficacy and quality of medicinal products. The availability, accuracy and clarity of drug information can affect the drug use decisions. The FGDOP does not have a welldeveloped system for pre-approval of medicines labels, promotional, and advertising materials. The terms and conditions under, which licenses to import, manufacture and distribute will be suspended, revoked or cancelled. This should be stringently applied to public, private and not-for-profit NGOs drug supplies organisations.

The predominant view, shared between the medicines' importers is the current pharmacy legislation to some extent satisfactory and managed to prohibit the marketing of low quality medicines. The recent postmarketing study carried by the National Drug Quality Control Laboratories, suggested the power of the current regulation is overestimated. The finding of this communication indicates the application procedures of the current measures to ensure the quality of medicines should be revisited. The technical complexity of regulations, political, commercial and social implications, makes necessary a degree of mutual trust between concerned stakeholders (i.e., suppliers, doctors, 
pharmacists, consumer representatives and government agencies).

\section{Rational for the Research}

The drug distribution network in Sudan during the past few years was in a state of confusion. It consists of open market, drug vendors (known as home drug store), community (private) pharmacies, peoples' pharmacies, private and public hospitals, doctors' private clinics, NGOs clinics, private medicines importers (wholesalers), public wholesalers (i.e., Central Medical Supplies and Khartoum State Revolving Drug Fund) and local pharmaceutical manufacturers. It is a common phenomenon in far states (e.g., Western and Southern states) to see street sellers or mobile sellers (hawkers) sell cigarettes, perfumes, orange and astonishingly medicines that range from Paracetamol and Aspirin tablets to antibiotics and anti-malarial drugs including injections. The medicines are usually left under the sun, and such conditions could facilitate the deterioration of the active ingredients.

The states' departments of pharmacy statutorily licensed community and Peoples' pharmacies. A superintending pharmacist, who is permanently registered with the Sudan Medical Council and licensed, oversees the pharmacy any time it is opened for business [19]. With such pharmacies there should not be any serious of the sale of fake drugs. Unfortunately, however there are many pharmacies working without qualified pharmacists.

This study is significant because the people right to health includes the right access to a reliable standard of health care and assurance the medicines received are not only genuine but also safe, effective, of good quality and affordable [20]. The Sudan government has designed various ways to protect the public against low quality medicines. It is expected to equip the departments of pharmacy especially in remote areas, poor states with material and trained staff to effectively perform duties.

A recent unpublished post-marketing surveillance revealed that $35 \%$ of the CMSPO samples and $16 \%$ of the private companies (registered products) samples obtained from different pharmacy shops failed to pass the quality test [20]. However, very few studies if any have been undertaken to evaluate the impact of the regulations put in place by the government long time ago.

This study should reveal strength and weaknesses of the legal pharmaceutical framework in Sudan from drug importers perspective. The findings of this investigation would be instructive to regulatory authorities in the developing countries. It also highlights how systematically the drug companies perceived the role of pharmacy regulations in assuring high quality of medicines and what suggestions (if any) they had to make in order to improve the regulatory framework.

\section{Methodology}

The study proposal was discussed to identify and improve the quality of medicines in Sudan. The survey was deliberately drug importers biased, as low quality medicines from informal sources will affect their business [21]. The authors then designed a self-administered questionnaire of 14 close-ended questions and one open question. The questionnaire was designed to address main six issues:

The quality of medicines.

The consequences of splitting of the regulatory authority functions between the Federal Ministry of Health (FMOH) and the Ministry of Animal Resources (MOAR). Views on the role of the recently established Federal Pharmacy and Poisons Board, and Pre- and PostMarketing Surveillance.

Decentralisation, and

Increased number of suppliers of non-registered medicines.

The final version of the questionnaire had been tested (three pharmacists working with drug companies in Sudan were asked to fill the questionnaire and feed the authors back whether there was unclear question or not). The questionnaire was tested to make sure all relevant issues were covered, pre-coded and adjusted before its distribution (Appendix 1).

The questionnaire was distributed to all forty participants at a seminar held in July 2004. Total numbers of drug importers companies were 175 in 2004. The seminar was organised by the FGDOP on the new proposal to limit (agree a ceiling for each item) the number of commercial brand product registered from each generic drug (the current situation is open). The owners and shareholders of drug companies were the participants. This was seen by the authors as a great opportunity to collect data of the drug importers' perspective on the quality of medicines. Hence, the study participants were so busy and it was very difficult to devote a time to be interviewed by the authors. In addition, the postal services in Sudan are poor (too slow and unreliable). 
Before the beginning of the seminar, the participants were requested by the secretariat to complete the questionnaire and hand it back to the secretariat before departure. The participants were informed it is anonymous questionnaire. The reasons given to the participants for filling out the questionnaire was to enable an academic research to assess the impact of the new Act on the quality of medicines. Finally, at the end of the seminar, the secretariat managed to get 30 questionnaires, representing $75 \%$ out of 40 distributed.

The information necessary to conduct this evaluation was collected from 30 pharmacists working with medicines' importing companies. Data gathered by the questionnaire were electronically analysed using Statistical Package for Social Sciences (SPSS) version 12.0 for windows.

\section{Result and Discussion}

The drug distribution network in Sudan consists of open market, drug vendors (known as home drug store), community (private) pharmacies, people's pharmacies, private and public hospitals, doctors' private clinics, NGOs clinics, private medicines importers (wholesalers), public wholesalers (i.e., Central Medical Supplies and Khartoum State Revolving Drug Fund) and local pharmaceutical manufacturers. The states' departments of pharmacy statutorily licensed community and Peoples' pharmacies. A superintending pharmacist, who is permanently registered with the Sudan Medical Council and licensed, oversees the pharmacy any time it is opened for business [22]. With such pharmacies there should not be any serious of the sale of fake drugs. Unfortunately however, there are many pharmacies working without qualified pharmacists [23].

During the last decade, the pharmacy workforces have witnessed a significant increase in the number of pharmacies, drug importing companies and pharmaceutical manufacturers as shown in Table 1. In the public sector, adoption of cost sharing policy as a mechanism of financing for essential medicines at full price cost requires far more expertise than simply distributing free medicines. This policy increases the demand for pharmacists in hospitals. The new concept of pharmaceutical care and recognition pharmacists as health care team members will boost the demand for the skilled pharmacist registered (PHRs). The Federal Ministry of Health (MOH) faces two major issues with the PHRs: first, the current shortage of pharmacists in the

Omer AM. It is Disturbing, in Spite of the Existence of Appropriate Legislation, Illegal Distribution of Medicines. Ann Adv Biomed Sci 2018, 1(1): 000108. public sector; secondly, the future role of pharmacists within the health cares system.

\begin{tabular}{|c|c|c|c|}
\hline Institutions & $\mathbf{1 9 8 9}$ & $\mathbf{2 0 0 3}$ & Increase in (\%) \\
\hline $\begin{array}{c}\text { Faculties of } \\
\text { Pharmacy }\end{array}$ & 1 & 7 & $600 \%$ \\
\hline $\begin{array}{c}\text { Registered } \\
\text { Pharmacists }\end{array}$ & 1505 & 2992 & $99 \%$ \\
\hline $\begin{array}{c}\text { Public Sector } \\
\text { Pharmacists }\end{array}$ & 162 & 300 & $85 \%$ \\
\hline $\begin{array}{c}\text { Hospital } \\
\text { Pharmacies }\end{array}$ & 205 & 304 & $48 \%$ \\
\hline $\begin{array}{c}\text { Community } \\
\text { Pharmacies }\end{array}$ & 551 & 779 & $41 \%$ \\
\hline $\begin{array}{c}\text { Drug Importing } \\
\text { Companies }\end{array}$ & 77 & 175 & $127 \%$ \\
\hline $\begin{array}{c}\text { Drug } \\
\text { Manufacturers }\end{array}$ & 5 & 14 & $180 \%$ \\
\hline
\end{tabular}

Table 1: Pharmacists labour market [23]

\begin{tabular}{|c|c|}
\hline State & Number of pharmacies \\
\hline $\begin{array}{c}\text { Department of Pharmacy } \\
\text { (DOP) Khartoum State* }\end{array}$ & 8 \\
\hline DOP-North Darfur & 7 \\
\hline DOP-Sennar & 2 \\
\hline DOP-North Kordofan & 5 \\
\hline DOP-South Kordofan & 7 \\
\hline DOP-White Nile & 2 \\
\hline DOP-Kassala & 7 \\
\hline DOP-River Nile & 3 \\
\hline DOP-Northern State & 3 \\
\hline DOP-Al Gezira* & 6 \\
\hline Total** & 50 \\
\hline
\end{tabular}

Table 2: Pharmacists' distribution at state levels [24]

${ }^{*}$ The Pharmacists who work with Revolving Drug Funds are not included.

${ }^{* *}$ Information about other.

States is not available (10 Southern states, 2 Darfur states, 2 Eastern states, 1 Blue Nile state, and 1 West Kordofan state).

Around 3000 pharmacists are registered in Sudan. Only $300(10 \%)$ works with the public sector. 25, 25, 20 pharmacists were employed in Khartoum, Khartoum North and Omdurman hospitals respectively. Some states (e.g., Southern states has only 2 pharmacists) were not included in Table 2. This anomaly seems to imply the number of pharmacists in the public sector (has not only been insufficient in absolute terms, but also has been 
inefficient in its distribution). This number will be depleted and the situation may be getting worse. One reason is migration to the private sector. The results are described in Figure 1.

In the absence of past baselines data, decisive conclusions should not be drawn from this article regarding the impact of the pharmaceutical regulations on ensuring good quality medicines. Nevertheless, the survey did serve to confirm the general impression about medicines of good quality on the Sudanese market.

$89 \%$ of respondents considered the medicines on the Sudanese market are generally of good quality. Although $55 \%$ of the study population either strongly agree $(21 \%)$ or agree (34\%) with the statement the drug legislations in Sudan prohibit marketing of low quality medicines. 35\% believe the transfer of authority to recently established the Federal Pharmacy and Poisons Board (FPPB) will undermine on medicines quality assurance system. $38 \%$ of the participants thought the replacement of the FGDOP by the FPPB will improve the medicines quality control system.

Only one-fourth of respondents were not very confident in current systems and safeguard to ensure the quality of medicines. $69 \%$ of respondents were somewhat confident in the FGDOP regulates and monitors quality of medicines. The majority $79 \%$ of respondents agree with the statement "decentralisation of licensing and inspection of pharmaceutical premises will improve the pharmaceutical control".

After the approval of the Pharmacy and Poisons Act 2001, the Ministry of Animal Resources (dominated by veterinarians) took the responsibility of registration of veterinary medicines and the licensing of the whole and retail sellers of veterinary medicines. As expected, 91\% of respondents thought, the splitting of drug registration between the $\mathrm{MOH}$ and the MOAR weakens the medicines control, compared with only $9 \%$ who thought the arrangement would improve the quality of medicines. One of the respondents added: "The splitting of the drug authority between $\mathrm{MOH}$, which according to the Sudan constitution is fully responsible for the public health and MOAR will create contradiction in lines of commands and public health would be compromised". $84 \%$ of respondents agreed with the statement "This new arrangement could cause conflict between two regulatory authorities" 93\% of participants either strongly agree $(73 \%)$ or agree $(20 \%)$ the increased number of non-registered medicines distributors will facilitate the marketing of low quality medicines (Figure 1). When asked about updated requirements of medicines registration, only $25 \%$ of respondents thought the updated requirements are not sufficient to prevent marketing of low quality medicines. Nearly three-quarters (71\%) agreed the pre-marketing surveillance is not enough to ensure the quality of medicines. The law regulating medicines was judged by the respondents as generally adequate (68\%).

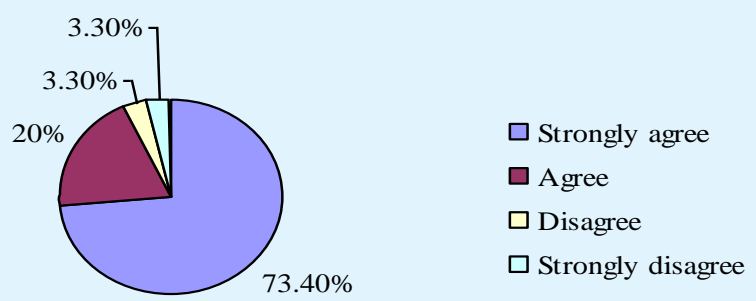

Figure 1: The increased numbers of non-registered medicines importers will facilitate the marketing of low quality medicines.

\section{Medicines Supply System}

The Act, for the first time in Sudan has given the responsibility of veterinary medicines to separate committees. The Ministry of Animal Resources took the law "in hand", and started the registration of veterinary medicines and the licensing of the veterinary medicines premises. The conflict in the shared authorities between the Ministry of Health and the chairman of the FPPB lead to the freezing of the Board since October 2002. The FGDOP continues in the process of medicines registration, inspection of the pharmaceutical premises and the licensing as before establishment of the FPPB.

The Act also obliges the states' governments to take all steps necessary to ensure compliance with marketing of registered medicines in licensed premises. But, the weaknesses of the regulatory infrastructure and lack of political commitment at state levels, the leakage of low quality, unregistered medicines to those states are highly suspected. This left the door widely opened for informal marketing of medicines particularly in far states. The states regulatory authorities should take the advantage of the legal authority granted by the Sudan constitution and the Pharmacy, Poisons, Cosmetics and the Medical Devices Act 2001 to enforce the regulations and increase the frequency of the inspection visits to drug companies and retail pharmacies. 
Experience has shown the poor regulation of medicines can lead to the prevalence of substandard, counterfeit, harmful and ineffective medicines on the national markets and the international commerce. The Sudanese pharmaceutical legal framework was described as one of the strictest pharmaceutical system in the region. One of the great loopholes in this system was found to be the increased number of non-registered medicines-governmental sources such as the Central Medical Supplies Public Organisation (CMSPO) and notfor-profit non-governmental Organisations (NGOs). Respondents were hopeful the double standard of rules enforcement would be lifted after the new national unity government take over, arguing the current situation in which public organisations (such as the CMSPO) sell nonregistered medicines to the private pharmacies could enhance trading of counterfeit medicines and create unfair competition environment.

One of the respondent reported, "It is disturbing, in spite of the existence of appropriate legislation, illegal distribution of medicines by the CMSPO. The CMSPO continues to flourish, giving the impression the government is insensitive to harmful effect on the people of medicines distribution unlawfully, and some are of doubtful quality". During the past three years the CMSPO started to sell unregistered medicines to the private pharmacies. The CMSPO practice (he added) will undermine the inspection and medicines control activities and ultimately jeopardise the health of the people taking medication.

Not surprisingly all respondents strongly agreed the increased number of sources of non-registered medicines will lead to entrance of low quality medicines. This result is inline with the WHO recommendation, which encourages the regulatory authorities and state members government to register all medicines before the marketing. The medicines imported by public sector organisations are not excluded [25].

The FGDOP should define the norms, standards and specifications necessary for ensuring the safety, efficacy and quality of medicinal products. The availability, accuracy and clarity of drug information can affect the drug use decisions. The FGDOP does not have a welldeveloped system for pre-approval of medicines labels, promotional, and advertising materials. The terms and conditions under, which licenses to import, manufacture and distribute will be suspended, revoked or cancelled. This should be stringently applied to public, private and not-for-profit NGOs drug supplies organisations.
The predominant view, shared between the medicines' importers is the current pharmacy legislation to some extent satisfactory and managed to prohibit the marketing of low quality medicines. The recent postmarketing study carried by the National Drug Quality Control Laboratories, suggested the power of the current regulation is overestimated [26]. The finding of this approach indicates the application procedures of the current measures to ensure the quality of medicines should be revisited. The technical complexity of regulations, political, commercial and social implications, makes necessary a degree of mutual trust between concerned stakeholders (i.e., suppliers, doctors, pharmacists, consumer representatives and government agencies).

Worldwide there are different systems for providing pharmacy services. Most countries have some element of state assistance, either for all patients or selected groups such as children, and some private provisions. Medicines are financed either through cost sharing or full private. The role of the private services is therefore much more significant. Nationally, there is a mismatch between the numbers of pharmacists and where are they worked, and the demand for pharmacy services. The position is exacerbated locally where in some areas of poor; there is a real need for pharmacy services, which is not being met and where pharmacists have little spare capacity. Various changes within the health-care system require serious attention be given to the pharmacy human resources need. In order to stem the brain drain of pharmacists, it is, however, necessary to have accurate information regarding the reasons that make the pharmacists emigrate to the private sector. Such knowledge is an essential in making of informed decisions regarding the retention of qualified, skilled pharmacists in the public sector for long time. There are currently 3000 pharmacists registered with the Sudan Medical Council of whom only $10 \%$ are working with the government. The pharmacist: population ratio indicates there is one pharmacist for every 11,433 inhabitants in Sudan, compared to the World Health Organisation (WHO) average for industrialised countries of one pharmacist for 2,300 inhabitants. The situation is particularly problematic in the Southern states where there is no pharmacist at all. The distribution of pharmacists indicates the majority are concentrated in Khartoum state. When population figures are taken into consideration all states except Khartoum and Gezira states are under served compared to the WHO average. This mal-distribution requires serious action as majority of the population is served in the public sector. This study 
reveals the low incentives, poor working conditions, job dissatisfaction and lack of professional development programmes as main reasons for the immigration to the private sector. The objective of this article is to highlight and provide an overview of the reasons that lead to the immigration of the public sector pharmacists to the private sector in Sudan. The survey has been carried out in September 2004. Data gathered by the questionnaires were analysed using Statistical Package for Social Sciences (SPSS) version 12.0 for windows. The result have been evaluated and tabulated in this article. The data presented in this paper can be considered as nucleus information for executing research and development for pharmacists and pharmacy. More measures must be introduced to attract pharmacists into the public sector. The emerging crisis in pharmacy human resources requires significant additional effort to gather knowledge and dependable data that can inform reasonable, effective, and coordinated responses from government, industry, and professional associations.

\section{Discussions}

In Sudan, with more than ten million people don't have adequate access to health care; twenty million inhabitants are without access to pharmacy, and a very low proportion of people being treated in hospitals. The investment, which is needed to fund the extension and improvement of these services, is substantial. Most governments in developing countries are ready to admit that they lack the financial resources for proper health and pharmacy schemes. Moreover, historically, bilateral and multilateral funding accounts for less than $10 \%$ of total investment needed. Thus the need for private financing is imperative.

Many healthy utilities in developing countries need to work in earnest to improve the efficiency of operations. These improvements will not only lead to better services but also to enhanced net cash flows that can be reinvested to improve the quality of service. Staff productivity is another area where significant gains can be achieved. Failure of subsidies to reach intended objectives is due, in part, to lack of transparency in their allocation. Subsidies are often indiscriminately assigned to support investment programmes that benefit more middle and high-income families, which are already receiving acceptable service. Consumption subsidies often benefit upper-income domestic consumers' substantially more than low-income ones. Many developing countries (Sudan is not an exception) are encouraging the participation of the private sector as a means to improve productivity in the provision of health and pharmacies services. Private-sector involvement is also needed to increase financial flows to expand the coverage and quality of services. Many successful private-sector interventions have been under taken. Private operators are not responsible for the financing of works, nonetheless they can bring significant productivity gains, which would allow the utility to allocate more resources to improve and extend services. Redressing productivity, subsidy and cross-subsidy issues before the private sector is invited to participate, has proven to be less contentious.

Despite the constraints, over the last decade the rate of implementation of rural and peri-urban pharmacy supplies and healthy programmes has increased considerably, and many people are now being served more adequately. The following are Sudan experience in pharmacy supply and healthy projects:

At community level:

- Participatory approaches in planning, implementation and monitoring.

- Establishment and training of reliable financial and maintenance management.

- Sensitive timing of health and hygiene education.

At state and national level:

- Integrated multi-sectoral approach development.

- Training approach and material development for state and extension staff.

- Continuing support from integrated multi-sectoral extension team.

- Establishment of technical support system.

- Multi-sectoral advisory group including training and research institutions.

- Development and dissemination of relevant information for state and extension staff.

\begin{tabular}{|c|c|}
\hline Reasons & Percent \\
\hline Job satisfaction & 80.8 \\
\hline Sense of ownership & 65.4 \\
\hline Training programme & 46.2 \\
\hline $\begin{array}{c}\text { Feeling of doing a public } \\
\text { job }\end{array}$ & 38.5 \\
\hline $\begin{array}{c}\text { Pensions and other } \\
\text { benefits }\end{array}$ & 7.7 \\
\hline
\end{tabular}

Table 3: Reasons for choosing public sector $(\mathrm{N}=26)$ 


\begin{tabular}{|c|c|}
\hline Reasons & Percent \\
\hline $\begin{array}{c}\text { High wages and incentives in the private } \\
\text { sector }\end{array}$ & 87.5 \\
\hline Private sector offers vehicles & 56.3 \\
\hline $\begin{array}{c}\text { The private give full treatment when } \\
\text { feeling ill }\end{array}$ & 50 \\
\hline Job satisfaction in the private & 6.3 \\
\hline
\end{tabular}

Table 4: 'Why are you intending to leave the public sector?' ( $\mathrm{N}=16)$

\begin{tabular}{|c|c|}
\hline Reasons & Percent \\
\hline Monetary issues & 69.2 \\
\hline Lack of recognition of what I have done & 57.7 \\
\hline Dim vision & 53.8 \\
\hline $\begin{array}{c}\text { Sense of instability } \\
\text { Those who work and those who don't are } \\
\text { equal }\end{array}$ & 53.8 \\
\hline Policy-makers don't care about pharmacy & 53.8 \\
\hline Lack of job satisfaction & 34.6 \\
\hline Political issues & 15.4 \\
\hline
\end{tabular}

Table 5: Reasons discourage you to continue with public sector $(\mathrm{N}=26)$

The respondents recommended continuing pharmacy professionals' development to assure the role of the pharmacists in the health care, creation of new jobs, increase the salaries of public sector pharmacists and activation of federal pharmacy and poisons board.

\section{Public Sector Pharmacists}

The total number of respondents from public sector was 26 pharmacists $(53.8 \%)$ of them were males. The majority $(73 \%)$ of respondents graduated within or after 1991. Most (69\%) of them had studied in Sudan. Surprisingly, (57\%) of pharmacists $(53.8 \%$ male) were employed in the private at some time in the past before joining the public sector. This is due to the fact some of the current pharmacy managers in Federal and Khartoum State Departments of Pharmacy had private sector experience. The top three reasons that de-motivate pharmacists who had experience with the private were lack of ownership feeling (21.4\%), sense of working for specific person $(21.4 \%)$ and job dissatisfaction $(14.3 \%)$. Most (80.8\%) of respondents joined the public sector due to job satisfaction and feeling of ownership (65.4\%) as illustrated in Table .3. In answering the question: 'Do you have intention to leave the public sector at some time in the future?' (61.5\%) of respondents answered 'Yes'. The vast majority $(87.5 \%)$ of them owing their intention to leave for better benefits in the private sector compared with the public sector as given in Table .4. Table .5 shows (69.2\%) of respondents mentioned monetary issues as one of the reasons discourages them from continuing with public sector [27].

\section{Private Sector Pharmacists}

The number of respondents from the private sector was $54(80 \%)$ of them were male. (77.8\%) had studied in Sudan and the majority (74\%) graduated during or after 1991. $32(59.3 \%)$ of the respondents worked with community pharmacy whereas, $22(40.7 \%)$ were drug companies employees. Salaries in the private sector ranged from LS 500,000 to LS 2,500,000 Sudanese pound (LS) or more (1 US\$ = LS 2500). 35 (65\%) pharmacists had previous public sector experience. In answering the question 'Why did you leave the public sector?' (51.4\%) of respondents had left the public sector because policymakers did not care of pharmacy (Table 5). The main reasons for choosing the private sectors mentioned by respondents are the salaries (61.8\%); the job satisfaction $(52.9 \%)$ and the vehicle $(26.5 \%)$ are shown in Table .6 and Figure 2.

Substantial percentage $(78.4 \%)$ of the respondents answer "yes" to the question: thinking about your own job; could you leave the private and join the public sector at some time in the future? Table .7 shows the reasons, which encourage pharmacists who were in the private sector (at the time of the study), and are willing to join the public sector.

\begin{tabular}{|c|c|}
\hline Reasons & Percent \\
\hline Policy makers don't care of pharmacy & 51.4 \\
\hline $\begin{array}{c}\text { Those who work and those who don't are } \\
\text { equal }\end{array}$ & 42.9 \\
\hline Low salaries and incentives & 42.9 \\
\hline Lack of recognition of what I have done & 31.4 \\
\hline Instability feeling & 28.6 \\
\hline Lack of job satisfaction & 28.6 \\
\hline Dim vision & 25.7 \\
\hline Political issues & 17.1 \\
\hline Others* & 28.6 \\
\hline
\end{tabular}

${ }^{*}$ No training, hospitals are without medicines and domination of doctors.

Table 6: 'Why do you leave the public sector?' ( $\mathrm{N}=35$ ) 
Annals of Advanced Biomedical Sciences

\begin{tabular}{|c|c|c|}
\hline No. & Reasons & Percent \\
\hline 1 & Salaries are better than public sector & 61.8 \\
\hline 2 & Job satisfaction & 52.9 \\
\hline 3 & Private sector offers vehicles & 26.5 \\
\hline 4 & Full treatment when feeling ill & 14.7 \\
\hline 5 & Others* $^{*}$ & 23.5 \\
\hline
\end{tabular}

Table 7: Reasons for choosing the private sector $(\mathrm{N}=34)$

${ }^{*}$ No jobs available in the public sector and mismanagement. It is easy to have a private job to increase the income and flexibility of working environment.

\begin{tabular}{|c|c|}
\hline Reasons & Percent \\
\hline Job satisfaction & 69.8 \\
\hline No feeling of working for specific person & 62.8 \\
\hline Overseas training & 62.8 \\
\hline Internal training & 55.8 \\
\hline Feeling of ownership & 48.8 \\
\hline Better salaries & 27.9 \\
\hline Others* & 18.6 \\
\hline
\end{tabular}

Table 8: 'What encourages you to join the public sector?' $(\mathrm{N}=43)$

*Public sector reserves rights when ill, job satisfaction, stability and fair competition.

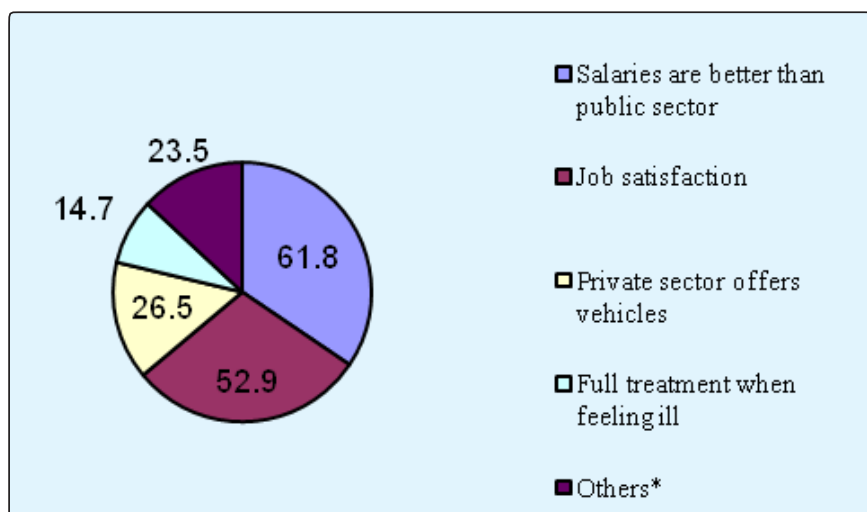

Figure 2: Reasons for preferring the private sector.

The most important reasons discourage the pharmacists who were in the private sector during the study period from joining the public sector are presented in Table 8.

\begin{tabular}{|c|c|}
\hline Reasons & Percent \\
\hline Monetary issues & 64.5 \\
\hline Dim vision & 51.6 \\
\hline Instability feeling & 38.7 \\
\hline Lack of job satisfaction & 19.4 \\
\hline Political issues & 12.9 \\
\hline Others* & 1.5 \\
\hline
\end{tabular}

Table 8a: 'Why didn't some private-sector pharmacists like to join the public sector?' $(\mathrm{N}=31$ )

*Government neglects pharmacists and the domination of doctors.

\section{Public Sector Pharmacy Workforces}

The public health sector reform seems to have undermined pharmacy human resources in health sector as often as making a positive contribution. Without motivated, competent, and well-funded pharmacy workforces, there is a dangerous infusion of money for establishing drugs revolving funds in different states. To address the national problem of access to essential medicines will be either misused or wasted, or both.

Challenges with respect to pharmacy human resources vary greatly between and within states, and associated with the political commitment of the states` government and their ministers of health. The public sectors' pharmacists in many states are adversely affected by sever under investment from the states and national funds, as well as external sources. For example, pharmacy budget from World Health Organisation (WHO) reduced from US\$ 200,000 in 2003 to only US\$ 93,000 in 2004. Driven by financial limitations, pharmacy workforces planning at federal and states ministries of health has been unable to match pharmacists requirements, the needs of community and the health system as whole.

It has been quite evident the civil service management system is detrimental to the retention of skilled pharmacists. Like other disciplines, the service affair authority determines the number of pharmacists' jobs in the public sector. It also sets salary scale and other incentives schemes in coordination with the Federal Ministry of Finance and Economic Planning. Although health professionals in hospitals tend to work in shifts and have to face different working conditions, the incentive system was not flexible enough to cope with differences between health professionals and other civil servants. Notably, the gap in the pharmacy workforces don't generally relate to pharmacists, but to pharmacy assistants who constitute the bulk of the workforces. The difficulties caused by low pharmacy staff numbers are 
compounded by morale problems, skill balances and geographical mal-distribution, most of which are related to poor human resources management. How can the ministry of health grapple successfully with the demands of pharmaceutical care crises and the requirements of transformed pharmacy profession, if it lacks the very foundation of pharmacy care - motivated, trained and supported pharmacists.

\section{Mal-Distribution}

Around 3000 pharmacists are registered in Sudan. Only $300(10 \%)$ works with the public sector. 25, 25, 20 pharmacists were employed in Khartoum, Khartoum North and Omdurman hospitals respectively. Some states (e.g., Southern states has only 2 pharmacists) were not included in Table .9. This anomaly seems to imply the number of pharmacists in the public sector (hasn't only been insufficient in absolute terms, but also has been inefficient in its distribution). This number will be depleted and the situation may be getting worse. One reason is migration to the private sector.

\section{Working Conditions}

Sudan like many developing countries, the essential working conditions is not met. Social or personal development opportunities are limited. Therefore, it is difficult for health professionals in general and pharmacists in particular to remain satisfied. The poor working conditions, remuneration and other factors pushed pharmacists out of the public sector.

\begin{tabular}{|c|c|}
\hline State & Number of pharmacists \\
\hline $\begin{array}{c}\text { Department of Pharmacy } \\
\text { (DOP) Khartoum State }\end{array}$ & 8 \\
\hline DOP-North Darfur & 7 \\
\hline DOP-Sennar & 2 \\
\hline DOP-North Kordofan & 5 \\
\hline DOP-South Kordofan & 7 \\
\hline DOP-White Nile & 2 \\
\hline DOP-Kassala & 7 \\
\hline DOP-River Nile & 3 \\
\hline DOP-Northern State & 3 \\
\hline DOP-Al Gezira* & 6 \\
\hline Total $^{* *}$ & 50 \\
\hline
\end{tabular}

*The Pharmacists who work with Revolving Drug Funds are not included. ${ }^{* *}$ Information about other

States is not available (10 Southern states, 2 Darfur states, 2 Eastern states, 1 Blue Nile state, and 1 West Kordofan state).

Table 9: Pharmacists' distribution at state levels
To be successful, user fee mechanisms must generally be accompanied by perceived quality improvements in services. The World Bank suggests the improvement in the quality of services would compensate the negative impact of prices. This implies that improved supply mechanisms for drugs are both prerequisites and outputs of successful programmes. The properly designed cost recovery programmes can encourage higher demand for modern health care and, as a result, higher level of utilisation. If all are true, it is unsurprising the utilisation of Sudan health services in the public sector was low during the 1980s and personnel, especially in peripheral health facilities, idle most of the time. In 1992, Sudan had introduced cost recovery measures as a part of its programme of economic reforms, following a course taken by many developing countries. During the 1990`s, Sudan initiated number of initiatives to establish medicine financing mechanisms as part of health reform process and decentralised decision-making at state level. In 1992, the government abolished the constitutional right of free health care. There is interest by the states to introduce a medicine financing mechanism based on the Revolving Drug Fund (RDF) experience of Khartoum State (KS).

\section{Nanomedicines}

Nanomedicine is defined as the medical application of nanotechnology. Nanomedicine can include a wide range of applications, including biosensors, tissue engineering, diagnostic devices, and many others. In the Center for Nanomedicine at Johns Hopkins, we focus on harnessing nanotechnology to more effectively diagnose, treat, and prevent various diseases. Our entire bodies are exposed to the medicines that we take which can lead to unpleasant side effects and minimize the amount of medicine that reaches the places where it is needed. Medications can be more efficiently delivered to the site of action using nanotechnology, resulting in improved outcomes with less medication.

For example, treating cancer with current chemotherapy delivery techniques is like spraying an entire rose garden with poison in order to kill a single weed. It would be far more effective to spray a small amount of poison, directly on the weed, and save the roses. In this analogy, a cancer patient's hair follicles, immune cells, and epithelia are the roses being poisoned by the chemotherapy. Using nanotechnology, we can direct the chemotherapy to the tumour and minimize exposure to the rest of the body. In addition, our nanotechnologies are more capable of bypassing internal 
barriers, further improving upon conventional nanotechnologies. Not only is our approach more effective at eradicating tumours under Research), but it also results in much higher quality of life for the patient.

Nanomedicine is the medical application of nanotechnology. Nanomedicine ranges from the medical applications of nanomaterials and biological devices to nano-electric devices, to nano-electronic biosensors, and even possible future applications of molecular nanotechnology such as biological machines. Current problems for nanomedicine involve understanding the issues related to toxicity and environmental impact of nano-scale materials and (materials whose structure is on the scale of nanometres, i.e. billionths of a metre). Functionalities can be added to nanomaterials by interfacing them with biological molecules or structures. The size of nanomaterials is similar to that of most biological molecules and structures; therefore, nanomaterials can be useful for both in vivo and in vitro biomedical research and applications. Thus far, the integration of nanomaterials with biology has led to the development of diagnostic devices, contrast agents, analytical tools, physical therapy applications, and drug delivery vehicles. Tracking movement can help determine how well drugs are being distributed or how substances are metabolized. It is difficult to track a small group of cells throughout the body, so scientists used to dye the cells. These dyes needed to be excited by light of a certain wavelength in order for them to light up. While different colour dyes absorb different frequencies of light, there was a need for as many light sources as cells. A way around this problem is with luminescent tags.

\section{Conclusion and Recommendation}

The study reveals the need for further research to find out how efficient the regulatory authorities at both federal and state levels are. The research also needed to discover whether or not counterfeit medicines are sold on the Sudanese market.

From the data obtained in this article some general inferences could be made:

1. The brad outlines remain intact, but preventing drug smuggling across national boarders (Sudan shares frontiers with 9 countries) is hard to police.

2. The enforcement of the Act and its regulation governing the manufacture, importation, sale, distribution and exportation of medicines are not adequate enough to control the illegal importation and sale of medicines in Sudan.
3. The splitting of the drug regulatory authority between two ministries and the marketing of unregistered medicines by public drug suppliers (namely the CMSPO, and RDFs), and NGOs undermine the quality of medicines and ultimately jeopardise the health of the people taking medication.

In the light of the findings the following recommendations could be useful at various levels:

There is an urgent need for government to implement the provisions of existing Act.

The government should adequately equip and fund the National drug Analysis laboratories to start active postmarketing surveillance.

A more spirited effort need to be made by the FGDOP and the States' Departments of Pharmacy to ensure all the medicines on the pharmacies' shelves are registered and come from legal sources.

The states' departments of pharmacies are not in existence should be re-established and invigorated. They should be adequately funded to be able to acquire the necessary facilities for their operations.

The CMSPO should stop importation, manufacture and distribution of unregistered medicines. It should also cease selling the tenders' product to the private pharmacies. The latter practice undermines the inspection outcomes, because it makes inspectors task too difficult (i.e., can not identify the source of medicine whether it is CMSPO or not).

The public sector is rigid, bureaucratic personnelmanagement practices, low incentives, poor job satisfaction and unsupportive work environment compared to the private sector. Such situation demoralised pharmacists and encourages them to join the private sector. Many (65\%) of surveyed private-sector pharmacists claimed they were public sector pharmacists migrated to the private sector. Although information on migration is sparse, anecdotal evidence persuasively underscores the problem. An internal flow of pharmacists plagues all states, since pharmacists move from poorer states to wealthier ones and from the public sector to the private. Strategies to meet current and future challenges in pharmacy human resources are urgently needed. Approaches that focus on the training of individuals, which do not take into account the job satisfaction (i.e. the nature of the work itself) and pharmacists' mobility, can enjoy only limited success. Increased production alone cannot compensate for weak motivation, high attrition and increasing mobility. To reverse decades of neglect, policy-makers in both (state and federal level) should begin now, first by recognising the problem and secondly 
by fixing it through the immediate implementation of potentially effective strategies. Although, we do not advocate the creation of new barriers to the movement of pharmacists between private and public sectors, steps should be taken to redress the unbalanced situation. Ten immediate steps are recommended:

- Large-scale advocacy is needed to achieve heightened political awareness within states and at federal level. One potential outcome of large-scale movement would be the beginnings of introduction of pharmacy care concept, which reshapes the pharmacy services around the patients in hospitals and community pharmacies. This concept will benefit the health care system users and motivate pharmacists to do a good job to their clients and employers. The employers need to foster an organisational culture that recognises and values staff contribution. Central to the delivery of effective recognition are employees' immediate bosses, where a participative and considerate management style is shown as a major predictive factor of retention.

- The Federal Ministry of Health (FMOH) needs to learn from the past experience of Khartoum, Red Sea, Northern, and Algadarif States and current Gezira State then, identify success stories. Pharmacists and their organisations, and Ministries of Health have not remained passive in confronting the crisis in pharmacy workforces. The goodwill and commitment of public sector pharmacists to provide quality care despite low wages $(30 \%$ of the average private salary) and medicines supply shortages at times of appalling conditions should not be overlooked.

- Pharmacist job satisfaction: Job satisfaction is how people feel about their jobs. Experiencing job dissatisfaction leads to withdrawal cognition and employee turnover. Job dissatisfaction can be caused in many ways, including high centralisation, routinisation, low integration, low communication and policy knowledge. Pharmacy education has a key role to prepare pharmacy student for practice and must anticipate the changing professional role. New strategies need to be developed with the participation of pharmacy professionals associations, unions, universities and ministries of health and higher education representatives to meet both; the short-term and long-term needs of pharmacists as pharmacy care providers. Technology will, no doubt give opportunity to join postgraduate studies (e.g., P.G. diploma or M.Sc. courses) from overseas via e-learning or continuing pharmacy professional development programmes.

- Salaries and incentives structure: This includes the process of creating new jobs, addressing low wages, as well as developing incentives structure that supports pharmacists over the course of their working lives. In order to stem the flow of pharmacists to the private sector and increase their performance, the Ministry of Health needs to pay incentives to its pharmacy staff on a semi-private basis. Introduction of the employment contract and the application of the incentive budget line opposite performance proved to be effective in Khartoum State experience. The obligations of each part (employer and employee) should be written in non-ambiguous language and transparent reward system should be in place. When transparency of reward system is poor, its credibility will be questioned and pharmacists might not respond to the explicit incentive system at all. IDS, 2000 pointed the lack of training and potential career development is a particularly important contributor to voluntary resignations. Uncompetitive pay is often debated as a reason for employee turnover. The perception of receiving a fair salary is a determinant of retention. It seems to be important both at the recruitment stage and subsequently as a determinant of retention rates is the perception that employees are receiving a fair salary. It is important to note this doesn't necessarily equate to a large salary, since people often compare themselves with peers in the same occupations or with friends and family rather than with better paid or higher skilled workers. Also, when promises are broken and expectations are perceived (haven't been met), employees take actions to withdraw from the organisation, which may include actually quitting jobs.

- Pharmacy staff motivation: In addition to financial incentives, Ministry of Health should continue to invest in improving the working conditions to ensure the suitable qualified and skilled pharmacists are retained for longer periods. Recruitment of qualified pharmacists (which may include looking outside the public services). A clear definition of job assignments (staff at hospitals' level enter into written contracts to perform according to $\mathrm{MOH}$ guidelines) and regular supervision will assist $\mathrm{MOH}$ to achieve a good staff performance. MOH should provide transport to pharmacists (senior and specialised pharmacists could be offered private vehicles) from their residence to the place of work to increase their motivation. Companypaid private medical insurance, and a company car for senior staff, child day care facilities, pension and retirement plans are the most desired and lead to employee retention.

- Redistribution of Pharmacy workforces: To address the problems of pharmacy profession in Sudan, an increase in access to essential medicines is insufficient. Far more 
important is the need to strengthen the pharmacy workforce in localities, states and federal health institutions to address the challenges and to use the resources and interventions for provision of effective pharmaceutical services.

- Small staff and efficient teamwork: The pharmacy workforces are divided into two levels (1) Department of pharmacies at Ministry of Health, and (2) Hospitals. The Department of pharmacy at state level should consist of 6 pharmacists at maximum and 25 at federal department of pharmacy including drug analysis laboratory. The hospitals department of pharmacies classified as follows:

(i) Group $A$ includes big hospitals (e.g., Khartoum and Omdurman hospitals). The numbers of pharmacists in Group A hospitals are 15 pharmacists in addition to pharmacy assistants and other supportive staff to cover all shifts. One manager, 3 pharmacist work in Drug Information Centre, three for internal hospital pharmacy, two in outpatient pharmacy, three in people pharmacy and one in clinical pharmacist;

(ii) Group B includes medium hospitals and capital cities hospitals (e.g., Ibrahim Malik, and Medani Hospitals). The Hospital Pharmacy Department (HPD) this group managed by 4 to 6 pharmacists;

(iii) Group $C$ includes small and rural hospitals. Two pharmacists could run the HPD in these hospitals. Paying attention to create more flexible and efficient system for PHRs management in the government institutions might help improve the condition of shortages of pharmacists in the public sector. The advantages of small staff can be easily managed, trained and financed, and teamwork could be developed. This also improves the performance and productivity of the public sector pharmacists thereby reduces the number of PHRs needed to provide satisfactory pharmaceutical services in the public sector institutions. The best indicators of staff retention are the fostering of friendships at work, and managers in health cares should take time to get knowing people and foster opportunities for friendship and socialising.

- National leadership at the highest level is essential and will only come to heighten the awareness of the fundamental importance of pharmacists in health care in general and in the pharmaceutical care in particular, and the development of new methods and strategies.

- Continuing pharmacy professional development: The most important element of National Drug Policy (NDP) and 25 years pharmacy strategy has yet to be tackled. $\mathrm{MOH}$ should fully recognise its 25 years pharmacy strategy goals could be achieved through people's (especially pharmacists) expertise. Appropriate training and development is the key to reach those goals and make strategy visions become reality. A wide variety of external (e.g., distance or e-learning in the developed world) and internal training and development programmes for pharmacists should be introduced. A pharmacist's career or pathway should be developed. A policy for active selection of training fields should be formulated according to the priorities of health care needs. The career development relies on individual training and development to enable employees to move into more challenging roles and can provide enhanced rewards for those who are promoted.

- Pharmacy staff discipline and accountability system: Disciplinary procedures, which provide a range of possible responses (from warnings through dismissal, depending on the severity and frequency of the offence should be clearly stated in the new work contracts). Pharmacy managers and team leaders in different settings (administration or care providing, at both state and federal levels) should be trained to invoke disciplinary procedures and to bring criminal charges when necessary.

Improving effectiveness of the public pharmacy is by switching resources towards areas of need, reducing inequalities and promoting better health. Unless there are clear incentives for pharmacists, they can move away from public sector.

Findings innovative approaches to stop brain drain of the pharmacists from the public sector and to increase their productivity and performance might be more appropriate strategies to solve the problem in Sudan. These strategies comprise, for instance, monitory incentives, continuing professional development, working condition and job satisfaction of civil service PHRs.

The study may help the Ministry of Health to better look at the real issues of PHRs in the public sector and formulate more relevant and useful policies and plans to retain qualified and skilled pharmacists in the public sector on a solid evidence base. Monitoring and evaluation of information provided to $\mathrm{MOH}$.

The data must be accurate and up to date. The study revealed low salaries, job dissatisfaction in relation to the pharmacy practice and bureaucracy, working conditions, lack of recognition for contribution at work, and lack of 
professional development training programmes are the main factors influencing the brain drain of the PHRs.

These factors affect PHRs immigration and retention concurrently rather than in insolation.

Given the time constraints required to get the new contracting arrangements in place, there is a risk that good practice developments in options for change for change field sites may not be used effectively (continue to evaluate and disseminate the lessons that emerge from these sites).

\section{Ethical Clearance and Data Protection Consent}

Before starting the data collection, ethical clearance was obtained from the Federal Ministry of Health (MOH)Research Ethics Committee. The first author signed the data protection consent and the respondents were informed it was an anonymous questionnaire and all the data collected are for the FGDOP assessment purpose. Nevertheless, the participants were also informed the data processing would not be used to support any decision-making and would not cause any damage, and distress them or to their business.

\section{Research Limitations}

The selection of one group of stakeholders and ignorance of the rest (such as the CMSPO, retail pharmacies, drug manufacturers, NGOs, consumers organisations, policy-makers, regulators, police, customs, doctors, other health care professionals, and health professional unions, etc.) were not included. This means great caution must be exercised in any extrapolation to a country level statistical analysis, and percentage given must be regarded as rough estimates.

\section{Reliability and Validity of The Research Instrument}

The sample chosen is indicative rather than fully representative and has been sized to be feasible in the time and resources available for the authors. However, the sample is thought to be sufficient to allow valid statistical analysis. Establishing the reliability and validity of measures are important for assessing their quality [7]. The mentioned time, and resources constraints did not allow the authors to test the reliability and validity of the research instrument.

\section{References}

1. Ministry of Health (MOH). Act 2001: Pharmacy, Poisons, Cosmetic and Medical Devices. Ministry of Health (MOH): Sudan 2001: 23-34.

2. Alubo SO (1994) Death for sale: A study of drug poisoning and deaths in Nigeria. Social Science \& Medicine 38(1): 97-103.

3. Andalo D (2004) Counterfeit drugs set alarm bells ringing. Pharmaceutical Journal 273(7316): 341.

4. Bryman A (2004) Social Research Method. (2 $\left.{ }^{\text {nd }} E d n\right)$. Oxford University Press. 15-24.

5. Elfadil AA (2005) Quality assurance and quality control in the CMSPO.

6. Erhun WO, Babalola 00, Erhun MO (2001) Drug regulation and control in Nigeria: The counterfeit drugs. Journal of Health and Population in Developing Countries 4(2): 23-34.

7. Gamal KM, Omer AM (2006) A prescription for improvement: A short survey to identify reasons behind public sector pharmacists' migration. World Health and Population 2006: 1-24.

8. Helling-Borda M (1995) The role and experience of the World Health Organisation in assisting countries to develop and implement national drug policies. Australian Prescriber 20 (Supp. 1): 34-38.

9. Jallow M (1991) Evaluation of national drug policy in the Gambia, with special emphasis on the essential drug programme. University of Oslo: Norway.

10. Lexchin J (1990) Drug makers and drug regulators: Too close for comfort. A study of the Canadian situation. Social Science and Medicine 31(11): 12571263.

11. Lofgren H, Boer $R$ (2004) Pharmaceuticals in Australia: developments in regulation and governance. Social Science and Medicine 58(12): 2397-2407.

12. Ministry of Health (MOH) 25 years Pharmacy Strategy (2002-2027). Khartoum: Sudan. Unpublished Report. 2003.

13. National Drug Policy (NDP) (1997) Ministry of Health (MOH): Sudan. 
14. Osibo 00 (1998) Faking and counterfeiting of drugs. West African Journal of Pharmacy 12(1): 53-57.

15. Ratanwijitrasin S, Soumerai SB, Weerasuriya K (2001) Do national medicinal drug policies and essential drug programmes improve drug use? A review of experiences in developing countries. Social Science \& Medicine 53(7): 831-844.

16. Rudolf PM, Bernstein IBG (2004) Counterfeit Drugs. New England Journal of Medicine 350(14): 13841386.

17. Shakoor O, Taylor RB, Behrens RH (1997) Assessment of the substandard drugs in developing countries. Tropical Medicines and International Health 2(9): 839-845.

18. Sibanda FK (2004) Regulatory excess: The role of regulatory impact assessment and the Competition Commission. In: Proceedings of the Pro-Poor Regulation and Competition Conference hosted by the Centre of Regulation and Competition (CRC), University of Manchester, UK, and the School of Public Management and Planning, University of Stellenbosch, Cape Town, 7-9 September 2004.

19. WHO (1991) Counterfeit drugs: guidelines for the development of measures to combat counterfeit drug. Geneva: World Health Organisation. WHO/EDM/ QSM/1990.1.

20. World Health Organisation / Drug Action Programme (WHO/DAP) (1996) Comparative analysis of international drug policies. Report from the second workshop Geneva. Pp: 114.

21. WHO (2009) International drug policies. Geneva: Switzerland.
22. Velpandian V, Elangovan S, Naansi Agnes L, Mohamed Musthafa M (2014) Clinical Evaluation of Justicia tranquebariensis L. In the Management of Bronchial Asthma. American Journal of Phytomedicine and Clinical Therapeutics AJPCT 2(9): 1103-1111.

23. Ravi Shankar K, Sita Ratna Kumari N, Kiranmayi GVN (2014) In vitro Study of Antioxidant and Antimalarial Activities of New Chromeno-Pyrano-Chromene Derivative, American Journal of Phytomedicine and Clinical Therapeutics AJPCT 2(9): 1169-1176.

24. Ramprabhu R, Jairam, Karthik A, Ravikanth K, Shivi Maini, Adarsh (2014) Evaluation of Regular Teat Sanitization Control Measures for Prevention of Sub Clinical Mastitis in Cattle, American Journal of Phytomedicine and Clinical Therapeutics, AJPCT 2(9): 1212-1216.

25. Abdeen M Omer (2011) The impact of the pharmaceutical regulations on the quality of medicines on the Sudanese market: importers' perspective, Prime Journals of Business Administration and Management (BAM) 1(9): 295302.

26. Abdeen M Omer (2013) Chapter 5: Regulatory privatisation, social welfare services and its alternatives, In: Advances in Medicines and Biology, Vol.72, Editor: Leon V. Berhardt, 2013 NOVA Science Publishers, Inc., pp. 69-86, New York, USA, 2013.

27. Abdeen M Omer, Gamal K. Ali, Chapter 98: Assessment of the Substandard Drugs in Developing Countries: The Impact of the Pharmaceutical Regulations on the Quality of Medicines on the Sudanese Market Importers' Perspective, In: Medicine Research Summaries (with Biographical Sketches), Volume 15, and Editors: Zhongwen Liáng and Bibao Zhang, pp. 213-224, 175-176, USA, 2017. 